with his selection on points of detail. A major criticism is the complete absence of references to original sources, apart from a list of twelve books recommended for supplementary reading.

J. S. Porterfield

\section{BIOLOGY OF DREAMING}

The Biology of Dreaming

(A Monograph in the Bannerstone Division of American Lectures in Living Chemistry.) By Ernest Hartmann. Pp. xiii +206 . (Springfield, Illinois: Charles C. Thomas, Publisher, 1967.) $\$ 9.75$.

SLEeping and dreaming are of increasing interest to a range of research workers from widely differing basic backgrounds. The information explosion of the past decade, due to energetic sleep research, has led to a situation where research is now reported in almost every journal at some time or another. It can therefore be very difficult at times to find what is being thought currently about some aspects of this research. Many sleep researchers are aware of this difficulty and have produced reviews, usually contained within suitable journals or more massive books.

Dr Hartmann has taken on the task of describing present ideas on the biological, clinical and some psychological aspects of the problem of dreaming.

Ho describes the basis for the experimental studies of sleep-although his illustrations in this section have not come out well. It is also most unfortunate that after pointing out-admirably-that the neurophysiological state in which most dreaming has been found has already twenty-two names, he adds his own-the " $D$ or dreaming state". The fact that he goes to pains to review at various points the data that dreams have been collected from the other type of sleep, now christened the "S state", emphasizes the semantic difficulty. Surely it is time we agreed on universal terminology.

After a short but comprehensive account of the "dream deprivation" experiments and discussion of the demand for the "D state", the author gives a very neutral account of the controversies of the possible chemical basis for this state. There are very full accounts of the association of dreaming with mental illness despite the apparent gaps and conflicts in this area. Association of the "D state" with physical illness is also interesting and I enjoyed his discussion of a possible connexion between the "D state" and psychosomatic illness, although our ignorance in this area is made apparent.

The biological importance and function of the "D state" are dealt with without bias at the expense of over-inclusion at times.

Obviously in this book there are instances where the current knowledge has outstripped the ideas present when the book was written, but these examples are minor.

I enjoyed the book and despite its short length and very comprehensive data did not get the feeling of compression. The bibliography is good.

It is, however, an expensive volume, much of which will be dated rapidly. I would see it as a good review which, made available by libraries, will carry its ideas to a wide range of people who otherwise might find difficulty in finding this material in the journals. J. I. EvaNs

\section{ECONOMIC ANTHROPOLOGY}

\section{Themes in Economic Anthropology}

Editcd by Raymond Firth. Pp. x+292. (London: Tavistock Publications, Ltd., 1967.) 45s. net.

CONTEMPORARY economic theory is bccoming increasingly divorced from reality and its arguments have assumed largely the character of futile intellectual jeux d'esprit. In so far as this volume is representative for the prevailing trend in economic anthropology-which it ought to be, considering that it is based on the collective wisdom of two scores of anthropologists assembled in conference in 1965 -it seems that many economic anthropologists are well on their way towards adopting the most deplorable features of contemporary economics-choice of deliberately abstruse aspects of their subjects and their obscurantist treatment.

The language of some of the essays in this book is admittedly still that of Marshall, Keynes and Malinowski, but others are dominated by the economic terminology invented for the purpose of deterring the layman from taking an interest. That the participants of the conference, while at pains to familiarize themselves with the teachings of sophisticated contemporary economists, missed out their elementary lessons seems to be indicated by the fact that none of those who pooled their resources at the conference corrected Mary Douglas when she attributed to Adam Smith a frequently quoted remark by John Stuart Mill about the difficulties of barter between a tailor and a baker.

Disregarding that minor error, Mary Douglas's essay on "Primitive Rationing: A Study in Controlled Exchanges" is a contribution of outstanding interest. But in spite of being an eminently lucid presentation of a subject of essentially practical interest, it must be classed among the intellectual jeux d'esprit. For the author uses her remarkable erudition, incisive analysis and clarity of exposition for a tour de force to prove an utterly absurd thesis-that primitive moneys serve the purpose of rationing. She failed to produce a single valid argument in support of her thesis. But the superb skill with which she presented her basically false case compels admiration, mingled as it is with regret for the waste of such a superb display of scholarship in the service of such an undeserving case.

Nothing could indicate more clearly the possibility of defending a wrong thesis in an impressive and convincing way than the fact that Mrs Douglas managed to convert such a formidable scholar as Raymond Firth, at any rate to the extent that, instead of rejecting her contention out of hand, he suggested in his opening essay that the analogy of primitive moneys to ration coupons offered "an intriguing set of criteria for discussion" (page 18). Had Professor Firth examined closely enough the factual evidence provided by Mrs Douglas I am sure he would have discovered that her ethnological instances are either perplexingly irrelevant or they prove exactly the opposite of what she seeks to prove.

Rationing is a system to ensure egalitarian distribution, while the evidence offered by Mrs Douglas conclusively reaffirms the generally known fact that the operation of primitive monetary systems results in increasingly unequal distribution. Such effect is inherent in these systems. This is certainly the case of the system on which she writes on the basis of first-hand knowledge, the use of raffia cloth units by the Lele. In the course of her field research in that community, embodied in her excellent monograph The Lele of Kasai, she found that most raffia cloth-which could be produced by anyone-tended to accumulate in the hands of a small number of rich old men. I could quote scores of instances of moneys operating in primitive communities that produced a similar effect. It puzzles me beyond words how a highly intelligent anthropologist like Mary Douglas can possibly imagine that such a system makes for egalitarianism. And since it does exactly the opposite, how can it be called rationing?

Mrs Douglas stated that among the Lele every man could issue his own ration coupon to himself. I failed to discover in her essay the strange process of reasoning by which she succeeded in convincing herself that virtually unlimited production of ration coupons "no more makes nonsense of the rationing analogy than it makes nonsense to speak of money when the unit of currency is freely 